Psychological Medicine, 1982, 12, 461-463

Printed in Great Britain

\title{
EDITORIAL
}

\section{The neuropsychiatric implications of low level exposure to lead ${ }^{1}$}

Lead may well be the oldest neurotoxin known to man; it clearly is the best studied. Because lead's hazards are man-made, their understanding and control offer an instructive paradigm which could be used with profit in the management of other pollutants.

Recently, attention has shifted from the severe and unequivocal brain damage induced by lead at high dose to the possibility that lesser doses may also cause central nervous system changes. These lower doses are experienced by large segments of the population, and in children it may be that the attendant CNS alterations express themselves as learning disorders, attentional deficits or behaviour problems (Byers \& Lord, 1943; Needleman et al. 1979; de la Burde \& Choate, 1975).

This idea is supported by a number of findings. The symptoms of lead poisoning-behaviour change, headache, malaise, abdominal pain and clumsiness - are non-specific and easily misdiagnosed. Mental retardation, learning disorders and behavioural problems tend to occur more commonly in areas of higher environmental lead. Blood lead levels greater than $60 \mu \mathrm{g} / \mathrm{dl}$ are universally acknowledged as toxic, and in many areas 5-10\% of children have levels equal to or greater than $30 \mu \mathrm{g} / \mathrm{dl}$ - certainly a slim margin of safety. Indeed, at $30 \mu \mathrm{g} / \mathrm{dl}$ a number of biochemical systems become deranged. In this range, for example, free erythrocyte protoporphyrin is elevated (Piomelli et al. 1977), and CNS activity of D-aminolevulinic acid dehydrase and adencyclase are depressed (Hernberg, 1976; Nathanson \& Bloom, 1975). While these findings, taken either individually or collectively, are not adequate to make the case for effects at low dose, they have spurred a number of epidemiological studies of the problem since the early 1970s. Attention has focused on younger children because they absorb more lead from the gut and are more vulnerable at the same internal dose.

Establishment of a causal nexus by epidemiological techniques is a difficult task, one made even more formidable when the outcomes under examination are subtle behavioural changes. Many factors can assault the child's brain during development, and many of these (for example, malnutrition, prematurity, increased infection) are associated with poverty. Exposure to lead is not limited to lower class children, but the poor do take in more lead. The incidence of such risks as malnutrition may correlate with lead, and thus confound its effects on outcome. Identification and control of the important confounders is essential if the effect of lead is to be measured. Other commonly encountered research difficulties which vex many studies are inadequate markers of exposure, insensitive outcome measures, and ascertainment bias (Needleman \& Landrigan, 1981).

Many studies have relied on blood lead levels to classify older children. Blood is a short-term storage system for lead (Rabinowitz et al. 1976) and may return to normal after significant exposure has ended, leading to misclassification of subjects. Some studies have relied upon group tests, screening tests and neurological examinations to measure outcome. The detection of subtle lead effects requires more sensitive and reliable instruments. Finally, subjects who participate in an outcome study may differ in some systematic way from those who refuse to participate. Both spurious relationships and false negative reports can result from this difficulty. Investigators should attempt to estimate both the strength and direction of bias in any population study.

Given these formidable design difficulties, it is not surprising that, while some studies have found effects of lead at a low dose (de la Burde \& Choate, 1975; Landrigan et al. 1975; Perino \& Ernhart, 1974; Needleman et al. 1979; Yule et al. 1981), others have not (Lansdown et al. 1974; Baloh et al. 1975; Hebel et al. 1976). Nor is it surprising that, given the high political and economic stakes attached to the control of lead, the discourse about the topic is often strident and highly polarized.

\footnotetext{
1 Address for correspondence: Professor Herbert L. Needleman, Department of Child Psychiatry and Pediatrics, University of Pittsburgh, Pittsburgh, PA 15213, USA.
} 
Sophistication in the design and execution of population studies has increased remarkably in the past few years. Two studies, one in the United States (Needleman et al. 1979) and one in Germany (Winneke et al. 1981), have addressed the above mentioned design issues. Both studies found psychological deficits associated with 'asymptomatic' low dose exposure to lead. Both studies employed lead levels in deciduous teeth to classify exposure or internal dose. Dental tissue offers the advantage of being a fixed storage site for lead and can indicate exposure reliably years after it has ceased. The American study employed an unbiased sample with respect to lead exposure and classroom performance ( $N=158$ children), controlled for 39 non-lead covariates, and found statistically significant differences on the WISC-R IQ scales, auditory and speech processing, and attentional performance. Teachers' rating scales showed an increase in maladaptive classroom behaviour that was dose related and did not appear to have a threshold.

Three questions have been repeatedly asked about this investigation. Because they extend to other studies in the field as well, they merit close examination. The difference in mean full scale IQ scores, while significant at the $P=0.03$ level, is only 4 points. Is this difference biologically significant? Does it not lose significance when compared with the conventional standard deviation of 15 points on the WISC-R? Secondly, since the incidence of pica was $30 \%$ in the high lead group and $11 \%$ in the low lead group, is not pica a marker for pre-existent behavioural deviation, and is lead level an effect rather than a cause of deficit? Finally, since some factor must have been at work to account for the lead burdens in the two groups, could this unknown, perhaps constitutional, factor not be the true determinant of behavioural outcome?

A four-point span between the means of two samples of $N=100$ and $N=58$ has a considerably greater consequence than a difference of similar magnitude between two individuals. In this study, as in others, when the mean of the distribution is shifted four points to the left, the proportion of children scoring in the deficient range-i.e. 80 or below - is increased threefold. Statistical tests take account of the standard deviation of the variable and thus reflect biological as well as statistical significance in this regard. The basis of most tests ( $t$-test, $F$ ratio) is the ratio between the observed difference between groups and the estimated standard error of the population mean or the within-group variance.

In the American study stratification on pica showed that it was not related to teachers' ratings, while dentine lead was (Needleman \& Bellinger, 1981). The final question asks whether different lead burdens do not derive from some important but unspecified a priori difference between high and low lead subjects. A large sample of children living in the same area will not all have the same body lead burden, but may be expected to display a probability distribution of this variable. This distribution may be normal, log-normal or take some other shape. The distribution in levels may be due to microenvironmental factors, nutritional factors or, indeed, constitutional differences such as differential rates of absorption, excretion, or sequestration of lead. Each individual's burden will be a weighted sum of these and other unmeasured factors. There is no a priori reason to believe that this sum is correlated with intelligence or behaviour. On the contrary, if the measured variables known to segregate with lead burden - for example, geographical residence, race and socio-economic status - are controlled, it is highly unlikely that any concatenation of remaining microenvironmental, nutritional and constitutional variables would be correlated with both residual lead burden and psychological outcome. This is, of course, subject to revision. Further investigation may yet reveal an unnamed factor which is highly correlated with lead and affects brain function. Until this unlikely event materializes, however, it is not necessary to posit unnamed ghosts in the epidemiological machinery. Occam's razor has served science in the past and works well here. Given the epidemiological studies which show a lead effect, and data from animal studies which support them, it should not be necessary to multiply causes. This seems particularly true if the causes have not been identified or measured.

When the limit to which epidemiological studies can be taken has been reached, animal models are employed to achieve control of variables and to look for underlying mechanisms. Here lead can be manipulated as an independent variable, the number of confounders reduced and brought under better control. Impaired learning at low doses of lead has been demonstrated in the rodent (Petit \& Alfano, 1979) and in the primate (Rice \& Willes, 1979). Delayed appearance of brain cytochromes 
(Bull et al. 1979) and delayed synaptogenesis (Averill \& Needleman, 1980) are among the changes reported to accompany administration of lead at low dose.

Obviously, conclusions from animal models cannot be applied to the human situation without some slippage, and human population studies can never achieve complete control of all variables. In the study of lead, the two disciplines work well in each other's lacunae, and each answers questions about lead's properties that the other cannot.

Many useful and intriguing questions about lead remain to be studied. Lead produces changes in the heme pathway similar in some ways to those found in acute intermittent porphyria (Moore \& Graham, 1980). Are the behavioural features of lead and porphyria related then to the same heme products? Lead crosses the placenta. The effects of lead exposure during pregnancy on reproductive function, on birth outcome and on offspring development are vital areas for further study. At the other developmental extreme, the effects of lead on the ageing process deserve investigation. Lead is sequestered in bone, and is generally metabolically inactive. In the later decades of life, bone demineralizes and lead becomes available to soft tissue and the brain. Are some of the changes in mentation that accompany ageing, and are assumed to be inevitable, related to this phenomenon?

A final question remains. Why, given an impressive quantity of data from both population studies and animal experiments which lead to a strong set of inferences about the toxicity of lead at low dose, has action to remove lead from the human environment been so halting? If regulatory agencies wait until the case is proven with mathematical certainty, millions of children will have paid the price of avoidable exposure. Physicians, and particularly psychiatrists, in the daily pursuit of their vocations, regularly make strong judgements, and take stern actions in the face of less than complete data bases. While studies should proceed on the actions of lead, effective abatement should move forward with pace.

HERBERT L. NEEDLEMAN

\section{REFERENCES}

Averill, D. \& Needleman, H. L. (1980). Neonatal lead exposure retards cortical synaptogenesis in the rat. In Low Level Lead Exposure: The Clinical Implications of Current Research (ed. $\mathrm{H}$. Needleman), pp. 201-210. Raven Press: New York.

Baloh, R., Sturm, R., Green, B. \& Gleser, T. (1975). Neuropsychological effects of chronic increased lead absorbtion. A controlled study. Archives of Neurology 32, 326-330.

Bull, R. J., Lutkenhoff, S. D., McCarty, G. E. \& Miller, R. G. (1979). Delays in the postnatal increase of cerebral cytochrome concentration in lead-exposed rats. Neuropharmacology 18, 83-92.

Burde, B. de la \& Choate, M. S. (1975). Early asymptomatic lead exposure and development at school age. Journal of Pediatrics 87, 638-664.

Byers, R. K. \& Lord, E. E. (1943). Effects of lead poisoning on mental development. American Journal of Diseases of Children 66, 471-494.

Hebel, J. R., Kinch, D. \& Armstrong, E. (1976). Mental capacity of children exposed to lead pollution. British Journal of Preventive and Social Medicine 30, 170-174.

Hernberg, S. (1976). Biochemical subclinical and clinical responses to lead and their relation to different exposure levels, as indicated by the concentration of lead in blood. In Effects and Dose-Response Relationships of Toxic Metals (ed. G. F. Nordberg), pp. 404-415. Elsevier: Amsterdam.

Landrigan, P., Whitworth, R. H., Baloh, R. W., Staehling, N. W., Barthel, W. F. \& Rosenblum, B. F. (1975). Neuropsychological dysfunction in children with chronic low-level lead absorbtion. Lancet i, 708-712.

Lansdown, R. G., Clayton, B. E., Graham, P. J., Shepherd, J., Delves, H. T. \& Turner, W. C. (1974). Blood lead level behavior and intelligence: a population study. Lancet i, 538-541.

Moore, M. R. \& Graham, D. J. M. (1980). Monopyrroles in porphyria, psychosis and lead exposure. International Journal of Biochemistry 12, 827-832.

Nathanson, J. \& Bloom, F. E. (1975). Lead-induced inhibition of brain adenyl cyclase. Nature $255,419-420$.
Needleman, H. L. \& Bellinger, D. (1981). The epidemiology of low level lead exposure. Journal of the American Academy of Child Psychiatry 20, 496-512.

Needleman, H. L. \& Landrigan, P. (1981). The health effects of low level exposure to lead. Annual Review of Public Health 2, 277-298.

Needleman, H. L., Gunnoe, C., Leviton, A., Reed, R., Peresie, H., Maher, C. \& Barrett, P. (1979). Deficits in psychologic and classroom performance of children with elevated dentine lead levels. New England Journal of Medicine 300, 689-695.

Perino, J. \& Ernhart, C. (1974). The relation of subclinical lead level to cognitive and sensorimotor impairment in black preschoolers. Journal of Learning Disabilities 7, 616-620.

Petit, T. L. \& Alfano, D. P. (1979). Differential experience following developmental lead exposure: effects on brain and behaviour. Pharmacology, Biochemistry and Behavior 11, 165-171.

Piomelli, S., Seaman, C. \& Zullow, D. (1977). Metabolic evidence of lead toxicity in 'normal' urban children. Clinical Research 25, 459A.

Rabinowitz, M., Wetherill, G. \& Kopple, J. (1976). Kinetic analysis of lead metabolism in healthy humans. Journal of Clinical Investigation 58, 260-270.

Rice, D. \& Willes, R. J. (1979). Neonatal low-level lead exposure in monkeys (macacca fasiculoaris): effect on two-choice non-spatial form discrimination. Journal of Environmental Pathology and Toxicology 2, 1195-1203.

Winneke, G., Brochhaus, A., Kramer, U., Ewen, U., Kujanek, G., Lechner, H. \& Janke, W. (1981). Neuropsychological comparison of children with different tooth lead levels. Preliminary report. In Proceedings of International Conference, Heavy Metals in the Environment, pp. 553-556. WHO: Amsterdam. CEP Consultants: Edinburgh.

Yule, W., Lansdown, R., Miller, I. B. \& Urbanowicz, M. (1981). The relationships between blood lead concentrations, intelligence and attainment in a school population: a pilot study. Developmental Medicine and Child Neurology 23, 567-576. 